\title{
Smart Energy Distribution System using Arduino\& GSM Module
}

\author{
Abhishek Singh ${ }^{1}$, Adiya Ashok ${ }^{2}$, Amrit Prakash ${ }^{3}$, Ayskant Mishra ${ }^{4}$, Dheeraj Singh ${ }^{5}$, Kuldeep Singh ${ }^{6}$, \\ Mr. Abhishek Kumar Gupta ${ }^{7}$ \\ Students, Electrical \& Electronics Department, IMS Engineering College, Ghaziabad, India $a^{1,2,3,4,5,6}$ \\ Assistant Professor, Electrical \& Electronics Department, IMS Engineering College, Ghaziabad, India ${ }^{7}$
}

\begin{abstract}
This research paper is based on Energy distribution which is fabricated for the transmission line distribution by using different technologies \& sensors. This paper represent our views over power distribution system by adopting smart way to meet future energy requirement. The main purpose of this paper is to describe you how this system works, how the device which is used in this system works \& how it help to power boards of nation to energy management throughout country. This is an electronic system which is implemented by the Arduino \& GSM Module to give command and receive feedback. This system uses the technique of power shedding to different region of the country. This system is fully automated \& able to work continuously after the detection of fault and starts route diverting of the power and recheck the tradition path is healed or not then shoot message on the register mobile number.the relay Module is started or tripped as per the command given by the Arduino UNO This system is easily implemented on the homes for the personal energy management to save their power consumption.
\end{abstract}

Keywords: Current Sensor ACS712, Relay Module 6V\&12V, GSM Module Sim900, RTC, AC to DC Power Supply.

\section{INTRODUCTION}

Electricity transmission and distribution systems are among the most important technologies serving the world today bringing clean and useful energy to meet the demand of end users in many parts of the world. However, in the light of concerns on energy security and access, environmentalimpacts of energy use (especially the threat of climate change) and depletion and rising costs of non-renewable energy resources, these existing energy distributionsystems (built primarily around large, centralized power generation plants) havebegun to show signs of age, inflexibility, vulnerability, high costs and inefficiencies. Much has to be done to address these challenges facing centralized and large scalepower transmission and distribution.Smart energy distribution system is the most recommended system in fast growing energy demand era .it is used for the purpose of automatic controlling, distribution and monitoring. For the rapid transmission and well calculated power shedding. The system have manual and automatic approach. At the same time, distributed energy resources (including renewable energy systems,distributed power generation, and integrated energy systems) are becoming increasingly widespread and important, and entail the development and use of new and innovative approaches and technologies in energy supply and distribution.

\section{CURRENT SENSOR ACS712}

The current sensor ACS712 provides economical and precise solutions for AC or DC current sensing in industrial, commercial, and communications systems. The device package allows for easy implementation by the customer. Typical applications include motor control, load detection and management, switched-mode power supplies, and overcurrent fault protection. The device is not intended for automotive applications.

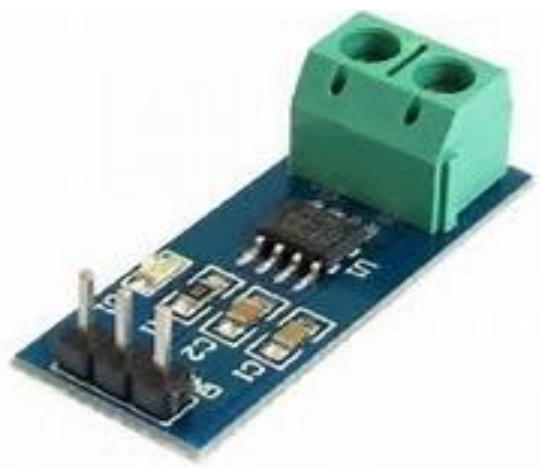


The device consists of a precise, low-offset, linear Hall sensor circuit with a copper conduction path located near the surface of the die. Applied current flowing through this copper conduction path generates a magnetic field which is sensed by the integrated Hall IC and converted into a proportional voltage.

Device accuracy is optimized through the close proximity of the magnetic signal to the Hall transducer. A precise, proportional voltage is provided by the low-offset, chopper-stabilized BiCMOS Hall IC, which is programmed for accuracy after packaging.

\section{RELAYMODULE}

Relays work on electromagnetism, When the Relay coil is energized it acts like a magnet and changes the position of a switch. The circuit which powers the coil is completely isolated from the part which switches ON/OFF, This provides electrical isolation. This is the reason we can control a relay using 5V's from an arduino and the other end of it could be running an $230 \mathrm{~V}$ appliance, the $230 \mathrm{~V}$ end is completely isolated from the $5 \mathrm{~V}$ arduino circuitry.

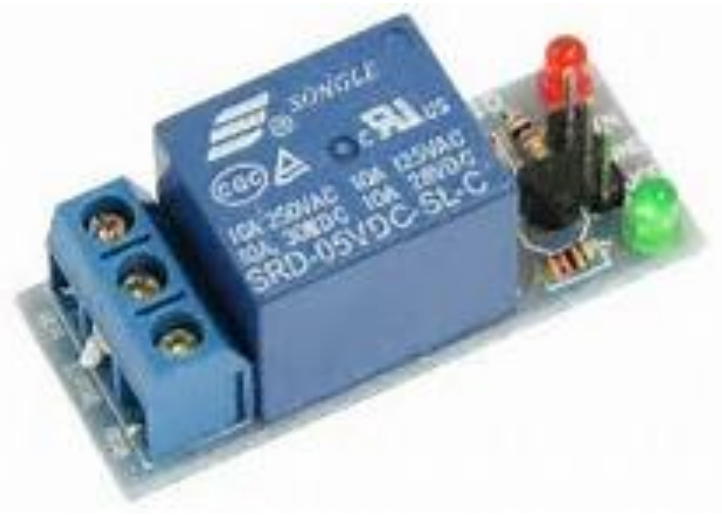

\section{ARDUINO BOARDS}

Arduino is a computer hardware and software tool that designs and manufactures microcontroller kits \& modules for building digital devices, control systems and interactive objects that can sense and control objects in the physical world. Arduino board designs use a variety of microprocessors and controllers. The boards are to be included with sets of digital and analog input/output ( $\mathrm{I} / \mathrm{O})$ ports that may be interfaced to various expansion boards (shields) and other circuits and sensors.

The boards feature serial communications interfaces, including Universal Serial Bus (USB) on some models, which are also used for the loading programs from the computers and also as a power supply for the board. The microcontrollers are typically programmed using a dialect of features from the programming languages $\mathrm{C}$ and $\mathrm{C}++$. The extension for using traditional compiler toolchains, the Arduino project provides an integrated development environment (IDE) based on the Processing language project.

\section{A. ARDUINO UNO}

Arduino Uno is a microcontroller board based on the ATmega328P (datasheet). It has 14 digital input/output pins of which 6 can also be used as PWM outputs, 6 analog inputs, a $16 \mathrm{MHz}$ quartz crystal, a USB port drive, a power jack port, an ICSP header and a reset button. It contains everything that needed for a microcontroller; to simply connect to a computer with a USB cable or to power it with a AC-to-DC converteradapter or battery to get started.

"Uno" means one in Italian and was chosen to mark the release of Arduino Software (IDE) 1.0. The Uno board and version 1.0 of Arduino Software (IDE) were the reference versions of Arduino, now evolved to newer releases. The Uno board is the first in a series of USB Arduino boards, and the reference model for the Arduino platform; for an extensive list of current, past or outdated boards see the Arduino index of boards.

\section{B. HARDWARE FEATURES}

- $5 \mathrm{~V}$

- 8-bit

- $16 \mathrm{MHz}$

- Automatic Voltage Regulator 


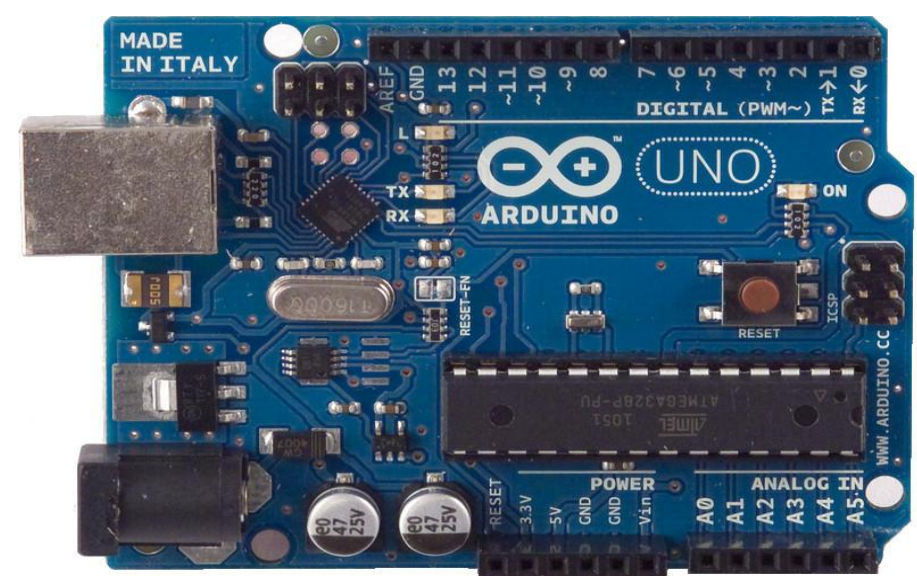

\section{GSMMODULESIM900}

This is a GSM/GPRS-compatible Quad-band cell phone, which works on a frequency of 850/900/1800/1900MHz and which can be used not only to access the Internet, but also for oral communication (provided that it is connected to a microphone and a small loud speaker) and for SMSs. Externally, it looks like a big package ( 0.94 inches x 0.94 inches x 0.12 inches) with L-shaped contacts on four sides so that they can be soldered both on the side and at the bottom. Internally, the module is managed by an AMR926EJ-S processor, which controls phone communication, data communication (through an integrated TCP/IP stack), and (through an UART and a TTL serial interface) the communication with the circuit interfaced with the cell phone itself.

The processor is also in charge of a SIM card ( 3 or 1,8 V) which needs to be attached to the outer wall of the module. In addition, the GSM900 device integrates an analog interface, an A/D converter, an RTC, an SPI bus, an $\mathrm{I}^{2} \mathrm{C}$, and a PWM module. The radio section is GSM phase $2 / 2+$ compatible and is either class $4(2 \mathrm{~W})$ at $850 / 900 \mathrm{MHz}$ or class 1 $(1 \mathrm{~W})$ at $1800 / 1900 \mathrm{MHz}$.

The TTL serial interface is in charge not only of communicating all the data relative to the SMS already received and those that come in during TCP/IP sessions in GPRS (the data-rate is determined by GPRS class 10: max. 85,6 kbps), but also of receiving the circuit commands (in our case, coming from the PIC governing the remote control) that can be either AT standard or AT-enhanced SIMCom type. The module is supplied with continuous energy (between 3.4 and $4.5 \mathrm{~V}$ ) and absorbs a maximum of 0.8 A during transmission.

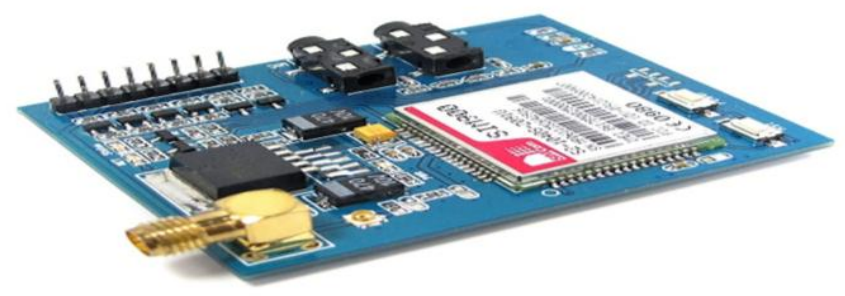

\section{HARDARE INSTALLATION}

The system hardware is so installed that it represents a section of smart energy distribution system. This system is reffered to as smart grid in some aspects.Here we have shown the energy supply to two cities from common grid or supply.The common supply is distributed between two relay,each of relay is connected to the step down transformer $(220 \mathrm{~V}-12 \mathrm{~V})$.The $12 \mathrm{volt}$ supply is given to both of the load relay and then power supply to cities as per the time scheduling of supply. All the four relay are interconnected.Ground of Arduino,Relays, Gsm module,current sensor and RTC are common to avoid malfunction.All of the devices get command from arduino.System works on power shedding,fault detecting and route diverting. The power allocation is done first to both the cities and time is allocated for two.As soon as the supply is given to the operating relay,it gives to transformer.The arduino give command that which relay will supply as the arduino receives the time data from RTC.Transformer give the supply tosecond relay which directly connected to it. This relay sends the current to current sensorACS712, it sence the current and gives consumption quantity to Arduino and the continues to flow into the cities.If the current limit overreach the allocated power, Then arduino shoots the message to the registered mobile number of overload condition through GSM module. As time of supply of first city over,Arduino sends the command to first relay to tripand then second relay gets command to active the supply to second city through current sensor.Meanwhile the supply of power to any of city and 
if there respective transformer destroys due to any of the reason,the Arduino send the command other relay and transformer supply the power through common relay .Meanwhile Arduino sends the command to GSM to shoot the message of route diverting to registered mobile number and after every defined time period Arduino check the condition whether the fault removed or not,as Arduino seeks to follow the tradition path, Whole system is interconnected hence it is called "Smart distribution system".

- Fully automatic system

- Path follower

- Range of current can be adjustable

\section{REAL TIME CLOCK}

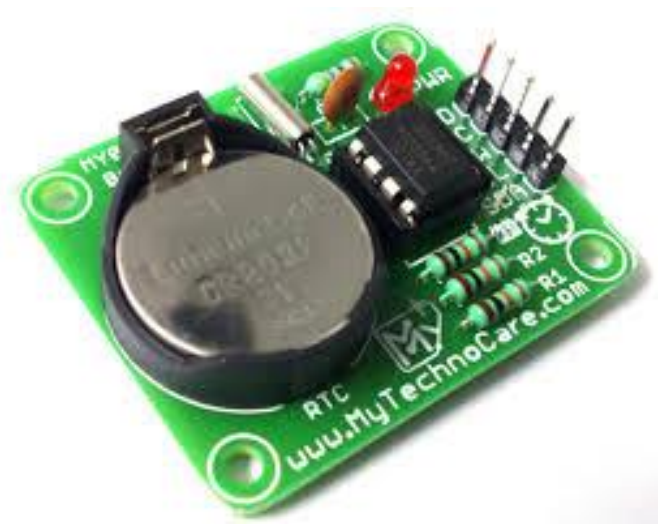

RTCs often have an alternate source of power, so they can continue to keep time while the primary source of power is off or unavailable. This alternate source of power is normally a lithium battery. Most RTCs use a crystal oscillator but some use the power line frequency In many cases, the oscillator's frequency is $32.768 \mathrm{kHz}$. This is the same frequency used in quartz clock and watches, and for the same reasons, namely that the frequency is exactly $2^{15}$ cycles per second, which is a convenient rate to use with simple binary counter circuits. The computer's power supply produces a pulse at logic voltages for either each half-wave or each zero crossing of AC mains. A wire carries the pulse to an interrupt. The interrupt handler software counts cycles, seconds, etc. In this way, it can provide an entire clock and calendar.The clock also usually formed the basis of computers' software timing chains; e.g. it was usually the timer used to switch tasks in an operating system. Counting timers used in modern computers provide similar features at lower precision, and may trace their requirements to this type of clock. (e.g. in the PDP-8, the mains-based clock, model DK8EA, came first, and was later followed by a crystal-based clock, DK8EC.). A software-based clock must be set each time its computer is turned on. Originally this was done by computer operators. When the Internet became commonplace, network time protocal were used to automatically set clocks of this type.

\section{Module Features}

- Accurate power mesurment

- Fully automatic setup

- Stable Module

\section{Uses}

- Fault Detection

- Interconnection of grid

- Can be used as home automation system

- Overload detection

\section{FUTURE ENHANCEMENTS}

- Compact \& Reliable Design of the system.

- Reduces the casualties.

- Reduces required man power.

- High end Controller is used with an AI with Decision Making abilities.

- High Range \& Accurate Sensors are Used.

- Live Surveillance can be implemented. 


\section{IMPLEMENTATION RESULT}

- Speed of Detection: -The sensor take the rough detection time of 2.8 seconds to 3 seconds to detecta fault and overload.

- Reduces the power loss.

- Monitored through SMS.

\section{CONCLUSION}

We have fabricated a robust and reliable energy distribution system to meet the country power need. We believe that our system is very simplified and have the features that other energy distribution system does not have at reliability level. Our system can be improved by doing the advancements according to the needs. The accuracy \& precision of the system can be improved by using multiple sensors $\&$ it will give good $\&$ accurate results with high precision.

\section{REFERENCES}

[1] Anorad Linear Motors, Information Brochure, Anorad, Hauppauge, New York, 2007,

[2] Boldea, I. and Nasar, S.A., Linear Motion Electromagnetic Systems, John Wiley \& Sons, New York, 1985.

[3] Boldea, I. and Nasar, S.A., Linear Electric Actuators and Generators, Cambridge University Press, New York, 2005.

[4] Compumotor Digiplan, Positioning Control Systems and Drives, Parker Hannifin Corporation, Rohnert Park, CA, 2011.

[5] Everes, W., Henneberger, G., Wunderlich, H., and Selig, A., A linear homopolar motor for a transportation system, 2nd International Symposium on Linear Drives for Industry Applications (LDIA'98), Tokyo, Japan, 1998, pp. 46-49.

[6] Gieras, J.F., Linear Induction Drives, Clarendon Press, Oxford, U.K., 1994.

[7] Gieras, J.F., Status of linear motors in the United States, International Symposium on Linear Drives for Industry Applications (LDIA'03), Birmingham, U.K., 2003, pp. 169-176.

[8] Gieras, J.F., Gientkowski, Z., Mews, J., and Splawski, P., Analytical calculation of electrodynamic levitation forces in a special-purpose linear induction motor, International Electric Machines and Drives Conference (IEMDC'11), Niagara Falls, Ontario, Canada, 2011 [on CD-ROM].

[9] Gieras, J.F., Piech, Z.J., and Tomczuk, B.Z., Linear Synchronous Motors: Transportation and Automation Systems, Taylor \& Francis (CRC Press), Boca Raton, FL, 2011.

[10] Hoang, E., Ahmed, A.H.B., and Lucidarme, J., Switching flux permanent magnet polyphase synchronous machines, 7th European Conference on Power Electronics and Applications (EPE'97), Vol. 3, Trondheim, Norway, 1977, pp. 903-908. 